\title{
Testing to Prevent Colon Cancer: Results From a Rural Community Intervention
}

Jobn M. Westfall, MD, MPH

Linda Zittleman, MSPH

Christin Sutter, BS ${ }^{1}$

Caroline B. Emsermann, $M S^{1}$

Elizabeth W. Staton, $M S^{1}$

Rebecca Van Vorst, MSPH

L. Miriam Dickinson, $P b D^{1}$

for the Community Advisory Council ${ }^{3}$

'Department of Family Medicine, University of Colorado Denver School of Medicine, Aurora, Colorado

${ }^{2}$ IPRO, Lake Success, New York

${ }^{3}$ High Plains Research Network, Aurora, Colorado

Conflicts of interest: authors report none.

\section{CORRESPONDING AUTHOR}

John M. Westfall, MD, MPH

High Plains Research Network

Department of Family Medicine

University of Colorado Denver School of

Medicine

Mail Stop F496, AO1

Aurora, CO 80045

jack.westfall@cohealthop.org

\begin{abstract}
PURPOSE Colon cancer is the second leading cause of cancer death in the United States. Despite tests that can detect and enable removal of precancerous polyps, effectively preventing this disease, screening for colon cancer lags behind other cancer screening. The purpose of this study was to develop and test a community-based participatory approach to increase colon cancer screening.
\end{abstract}

METHODS Using a community-based participatory research approach, the High Plains Research Network and their Community Advisory Council developed a multicomponent intervention-Testing to Prevent Colon Cancer-to increase colon cancer screening. A controlled trial compared 9 intervention counties in northeast Colorado with 7 control counties in southeast Colorado. We performed a baseline and postintervention random digit-dial telephone survey and conducted both intent-to-treat and on-treatment analyses.

RESULTS In all, 1,050 community members completed a preintervention questionnaire and 1,048 completed a postintervention questionnaire. During the study period, there was a $5 \%$ absolute increase in the proportion of respondents who reported ever having had any test in the intervention region (from $76 \%$ to $81 \%)$ compared with no increase in the control region (77\% at both time points) $(P=.22)$. No significant differences between these groups were found in terms of being up to date generally or on specific tests. The extent of exposure to intervention materials was associated with a significant and cumulative increase in screening.

CONCLUSIONS This community-based multicomponent intervention engaged hundreds of community members in wide dissemination aimed at increasing colorectal cancer screening. Although we did not find any statistically significant differences, the findings are consistent with an intervention-related increase in screening and provide preliminary evidence on the effectiveness of such interventions to improve colon cancer screening.

Ann Fam Med 2013;500-507. doi:10.1370/afm.1582

\section{INTRODUCTION}

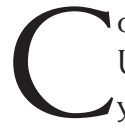

olon cancer is the second leading cause of cancer death in the United States and accounts for more than 50,000 deaths each year. ${ }^{1,2}$ Detection and removal of a polyp that may develop into cancer makes colon cancer one of the few preventable cancers, and early detection dramatically improves long-term survival. ${ }^{3,4}$ The combination of the prevention of and improved survival of this cancer through early detection provides strong rationale for promoting screening nationwide. ${ }^{5}$

Despite the availability of effective tests, screening for colorectal cancer remains low with just $53 \%$ of the eligible population nationwide reporting screening with endoscopy. ${ }^{6}$ Screening rates in Colorado are no exception: only $36 \%$ of eligible individuals report having had a fecal occult blood test (FOBT) in the past 2 years, and just $49 \%$ reported they have ever had a sigmoidoscopy. ${ }^{7}$ The Colorado Cancer Plan calls for screening of $75 \%$ of eligible Coloradoans within guideline recommendations. ${ }^{8}$ Much of the state is rural, however, and rural communities with a 
long distance to health care services may have unique barriers that increase residents' risk of poor outcomes. ${ }^{9}$

In 2004, the Guide to Community Preventive Services ${ }^{10}$ reported there was insufficient evidence to recommend small or large media education or community-wide multicomponent interventions to improve colorectal cancer screening. Aware that the combination of proven screening techniques in conjunction with low overall screening rates presented the opportunity to immediately reduce the number of deaths from colorectal cancer, the High Plains Research Network (HPRN) and its Community Advisory Council (CAC) chose to develop a program using a multicomponent intervention to improve colorectal cancer screening in rural and frontier eastern Colorado.

\section{METHODS}

Housed in the Department of Family Medicine at the University of Colorado Denver Anschutz Medical Campus, the HPRN is a geographically based practicebased research network covering nearly 30,000 square miles in 16 counties of eastern Colorado. The network consists of a collaboration between 16 community hospitals, 55 practices, 120 primary care clinicians, 20 nursing homes, several public health departments, and about 145,000 residents. Only rural and frontier counties are included. The HPRN's active CAC includes local farmers, ranchers, school teachers, and other community members to help guide the research and ground it in real patient experience.

The project used a community-based participatory research approach to develop and test a message and dissemination model aimed at increasing colon cancer screening in rural and frontier communities. The CAC was joined by 2 local physicians, 2 health department representatives, and a hospital administrator, and led the development of all aspects of the project, including assisting with analysis, interpretation of results, and dissemination of the findings. ${ }^{11-15}$

The intervention, Testing to Prevent Colon Cancer, consisted of an awareness and educational campaign that encouraged local residents aged 50 years or older to talk to their clinician about colon cancer testing. The CAC developed a 4-point message to address key catalysts of behavior change, including relevance, education, facilitation/encouragement, and action. The main messages were (1) colon cancer is the second leading cause of cancer death in the United States, (2) colon cancer is preventable, (3) testing is worth it, and (4) talk to your doctor today.

These messages were incorporated into intervention materials, most of which were available in both English and Spanish. The CAC selected a dissemina- tion strategy that tapped into the communication culture of rural communities, including the use of local community members in program components, local newspapers, and adaptations of familiar small-print materials, and local organizations that are common and valued in rural communities.

After a small pilot study, the full intervention was rolled out in 9 counties in 4 waves over 18 months. The controlled trial used a quasi-experimental, repeated cross-sectional ecologic design. The intervention group consisted of the 9 contiguous northeast Colorado counties, and the control group consisted of 7 contiguous southeast Colorado counties.

We conducted random digit-dialing telephone surveys at baseline and follow-up to assess colon cancer knowledge and screening behaviors. At baseline, we included questions to assess the exposure to health and safety messages. We included questions about each of 5 screening tests (colonoscopy, sigmoidoscopy, FOBT, virtual colonoscopy, and barium enema) and asked if and when respondents had undergone each test. The survey instruments were reviewed by the CAC and pilot-tested on persons in the target age-group.

This project was approved by the institutional review board at the University of Colorado Denver.

A Colorado media and market research firm conducted both the random digit-dialing interviews using an enriched sample of telephone numbers of households with persons of eligible age. After making telephone contact with a prospective household, the interviewers took a census of the age-eligible adults. They used the modified Kish method ${ }^{16}$ to randomly select 1 qualified household member to participate. Three counties with fewer than 30 respondents after the initial wave of calls were oversampled to ensure a minimum of 30 completed interviews per county. In order for estimates to be representative of the population, responses of participants from the 3 oversampled counties were weighted by the county population percentage of residents aged 50 years or older. The follow-up survey was completed 30 months after the baseline survey allowing for program development, full intervention, and adequate time to get tested.

We conducted 3 major analyses. First, we compared changes in screening behaviors within the intervention region. Second, we conducted an intent-to-treat analysis to compare the changes in screening behaviors between the intervention and control regions. Third, because of considerable contamination of our control region with intervention materials, we measured the impact of exposure to intervention materials on screening.

We undertook population descriptive statistics and used 2-sample $t$ tests for continuous variables and $\chi^{2}$ tests for categorical variable. For each screen- 
ing option, we compared demographic variables and whether the respondent ever had the test or was up to date on the test. Up-to-date status was determined based on the current guidelines. We performed multivariate logistic regression analyses to determine screening behavioral changes over time between respondents in control vs intervention regions. The models were adjusted for time point (baseline vs follow-up), exposure (intervention vs control county), and the test-by-exposure interaction to determine differential change in testing behavior. In addition, the models were also adjusted for sex, race (white non-Hispanic vs Hispanic), age (<65 years, $\geq 65$ years), and income ( $<\$ 35,000, \geq \$ 35,000$, no response). All analyses were completed in SAS (SAS Institute Inc). We also collected billing data from local hospitals to determine the number of endoscopy services they provided between 2000 and 2007 per region.

\section{RESULTS}

Analyses were based on 1,050 surveys completed at baseline and 1,048 completed at follow-up. The intervention and control regions were similar, except that the former had a higher percentage of non-Hispanic whites (93\% vs 78\%, $P<.01$ ). This difference reflects current differences in the general populations.

The baseline and follow-up samples were similar except for a few minor differences (Table 1). Follow-up respondents had a slightly lower percentage of Hispanics and a higher percentage who declined to provide their income. Within just the control region, the follow-up respondents were less likely to report Hispanic ethnicity $(18 \%$ at baseline vs $12 \%$ at follow-up, $P=.03$ ).

Within the intervention region, the proportion of respondents reporting that they had ever had any colorectal cancer screening test was an absolute 5\% higher at follow-up (increasing from $76 \%$ to $81 \%$, $P=.05)$, while the proportion up to date on any test increased by an absolute $9 \%$ (from $60 \%$ to $69 \%, P<.01)$. Eleven percent more respondents reported they had ever had a colonoscopy (43\% baseline to $54 \%$ followup, $P<.001)$, and $14 \%$ more reported being up to date on colonoscopy (from 38\% to $52 \%, P<.001)$. There were no changes from baseline in rates of sigmoidoscopy, FOBT, virtual colonoscopy, or barium enema. The percentage of respondents who had never had a test but planned to get one increased from $16 \%$ at baseline to $28 \%$ at follow-up $(P=.05)$.

\section{Intent-to-Treat Analysis}

An intent-to-treat analysis compared changes in selfreported screening rates among respondents in the intervention region vs control region (Table 2). Both regions experienced an increase in some screening tests
Table 1. Demographics of Respondents at Baseline and Follow-up

\begin{tabular}{|c|c|c|c|}
\hline Characteristic & $\begin{array}{c}\text { Baseline } \\
(n=1,005) \\
\text { No }(\%)\end{array}$ & $\begin{array}{c}\text { Follow-up } \\
(n=1,000) \\
\text { No. }(\%)\end{array}$ & $P$ Value \\
\hline Age, y & & & .66 \\
\hline $50-64$ & $524(52.2)$ & $511(51.1)$ & \\
\hline $65-70$ & $289(28.7)$ & $273(27.3)$ & \\
\hline $75-84$ & $164(16.3)$ & $179(17.9)$ & \\
\hline$\geq 85$ & $27(2.7)$ & $36(3.5)$ & \\
\hline Declined & $1(0.1)$ & $1(0.1)$ & \\
\hline Sex & & & .94 \\
\hline Male & $333(33.2)$ & $330(33.0)$ & \\
\hline Female & $672(66.8)$ & $670(67.0)$ & \\
\hline Race & & & .43 \\
\hline White & $886(88.1)$ & $896(89.6)$ & \\
\hline African American & $2(0.2)$ & $1(0.1)$ & \\
\hline Asian & $3(0.3)$ & $1(0.1)$ & \\
\hline $\begin{array}{l}\text { Native Hawaiian/other Pacific } \\
\text { Islander }\end{array}$ & $5(0.5)$ & $1(0.1)$ & \\
\hline American Indian/Alaska Native & $15(1.5)$ & $10(1.0)$ & \\
\hline Other & $72(7.2)$ & $69(6.9)$ & \\
\hline Don't know/declined & $22(2.2)$ & $23(2.3)$ & . \\
\hline Ethnicity & & & .06 \\
\hline White non-Hispanic & $839(83.5)$ & $874(87.4)$ & \\
\hline Hispanic & $101(10.0)$ & $73(7.3)$ & \\
\hline Other non-Hispanic & $53(5.3)$ & $40(3.9)$ & \\
\hline Don't know/declined & $12(1.2)$ & $14(1.4)$ & \\
\hline Education level & & & .09 \\
\hline High school or less & $412(41.0)$ & $397(39.7)$ & \\
\hline $13-16$ years & $443(44.1)$ & $485(48.5)$ & \\
\hline$\geq 17$ years & $147(14.6)$ & $114(11.4)$ & \\
\hline Don't know/declined & $4(0.3)$ & $4(0.4)$ & \\
\hline Income & & & .01 \\
\hline$<\$ 20,000$ & $282(28.1)$ & $240(24.0)$ & \\
\hline$\$ 20,000-\$ 49,000$ & $372(37.0)$ & $345(34.5)$ & \\
\hline$\$ 50,000-\$ 74,999$ & $126(12.6)$ & $125(12.5)$ & \\
\hline$\geq \$ 75,000$ & $78(7.8)$ & $103(10.3)$ & \\
\hline Don't know/declined & $146(14.5)$ & $187(18.7)$ & \\
\hline Employment & & & .22 \\
\hline Employed/self-employed & $438(43.6)$ & $394(39.4)$ & \\
\hline Unemployed/unable to work & $76(7.5)$ & $75(7.4)$ & . \\
\hline Homemaker & $49(4.9)$ & $66(6.6)$ & \\
\hline Retired & $435(43.3)$ & $458(45.8)$ & \\
\hline Other & $8(0.8)$ & $7(0.7)$ & \\
\hline
\end{tabular}


Table 2. Changes in Colon Cancer Screening Behavior From Baseline to Follow-up: Intervention vs Control

\begin{tabular}{|c|c|c|c|c|c|}
\hline \multirow[b]{2}{*}{$\begin{array}{l}\text { Weighted } \\
\text { Variable }\end{array}$} & \multicolumn{2}{|c|}{$\begin{array}{c}\text { Intervention } \\
\text { Region, \% } \\
(n=1,018)\end{array}$} & \multicolumn{2}{|c|}{$\begin{array}{l}\text { Control } \\
\text { Region, \% } \\
(n=988)\end{array}$} & \multirow{2}{*}{$\begin{array}{c}\text { Difference } \\
\text { in Change, } \\
P \text { Value }\end{array}$} \\
\hline & $\begin{array}{l}\text { Baseline } \\
(n=518)\end{array}$ & $\begin{array}{l}\text { Follow-up } \\
(n=500)\end{array}$ & $\begin{array}{l}\text { Baseline } \\
(n=487)\end{array}$ & $\begin{array}{l}\text { Follow-up } \\
(n=501)\end{array}$ & \\
\hline \multicolumn{6}{|l|}{ Any test } \\
\hline Ever had & 76 & 81 & 77 & 77 & .22 \\
\hline Up to date & 60 & 69 & 57 & 65 & .82 \\
\hline Plans to have & 16 & 28 & 15 & 17 & .18 \\
\hline \multicolumn{6}{|c|}{$\begin{array}{l}\text { Fecal occult blood } \\
\text { test }\end{array}$} \\
\hline Ever had & 61 & 63 & 64 & 60 & .11 \\
\hline Up to date & 29 & 29 & 34 & 29 & .29 \\
\hline Plans to have & NA & NA & NA & NA & NA \\
\hline \multicolumn{6}{|l|}{ Sigmoidoscopy } \\
\hline Ever had & 35 & 35 & 32 & 31 & .72 \\
\hline Up to date & 30 & 30 & 25 & 25 & .70 \\
\hline Plans to have & 5 & 7 & 5 & 7 & .73 \\
\hline \multicolumn{6}{|l|}{ Colonoscopy } \\
\hline Ever had & 43 & 55 & 42 & 52 & .70 \\
\hline Up to date & 38 & 52 & 37 & 49 & .78 \\
\hline Plans to have & 9 & 15 & 8 & 17 & .63 \\
\hline \multicolumn{6}{|l|}{ Endoscopy } \\
\hline Ever had & 53 & 62 & 50 & 58 & .83 \\
\hline Up to date & 47 & 58 & 43 & 53 & .86 \\
\hline Plans to have & 8 & 18 & 9 & 19 & .54 \\
\hline \multicolumn{6}{|l|}{ Barium enema } \\
\hline Ever had & 27 & 25 & 30 & 23 & .31 \\
\hline Up to date & 13 & 11 & 12 & 8 & .38 \\
\hline Plans to have & NA & NA & NA & NA & NA \\
\hline \multicolumn{6}{|c|}{ Virtual colonoscopy } \\
\hline Ever had & 15 & 15 & 11 & 11 & .83 \\
\hline Up to date & 10 & 11 & 9 & 8 & .91 \\
\hline Plans to have & NA & NA & NA & NA & NA \\
\hline \multicolumn{6}{|c|}{ NA = not applicable. } \\
\hline \multicolumn{6}{|c|}{$\begin{array}{l}\text { Note: Models for "ever had" and "up to date" were adjusted for intervention group; time; time-by-intervention } \\
\text { group interaction; and respondent's age, sex, race, and income; these analyses included all respondents. Models } \\
\text { for "plans to have" were adjusted for intervention group, time, and time-by-intervention group interaction; these } \\
\text { analyses included only respondents who never had the test performed. }\end{array}$} \\
\hline
\end{tabular}

$64 \%$ to $60 \%(P=.11)$. There was an increase in the percentage of respondents who reported ever having either sigmoidoscopy or colonoscopy in both the intervention region, from $53 \%$ to $62 \%$, and the control region, from $50 \%$ to $58 \%(P=.83)$.

We completed a separate analysis restricted to communities in the first wave of the intervention as they had the longest period of time between the intervention and follow-up. These communities had a larger increase in screening rates than both the remaining intervention communities and the control communities (Figure 1). There was an increase among wave 1 respondents in the proportion who reported ever having had any test (from $70 \%$ to $78 \%$ ), being up to date on any test (from $51 \%$ to $62 \%$ ), and planning to get tested (from 15\% to $24 \%)$. Colonoscopy testing rose dramatically (ever had colonoscopy, from $33 \%$ to $47 \%$, and up to date, from $32 \%$ to $46 \%$ ) and the combined measure of sigmoidoscopy or colonoscopy also rose in these communities for both reports of every having had the test (from $41 \%$ to $55 \%$ ) and being up to date (from $40 \%$ to $54 \%$ ).

\section{Exposure Analysis}

The intent-to-treat analysis showed an increase in screening in both intervention and control

from baseline to follow-up. Most importantly, there was a $5 \%$ increase in the proportion of respondents who reported ever having had any test (from $76 \%$ to $81 \%)$ in the intervention group but no increase in the control group (77\% at both time points), although this difference did not reach statistical significance $(P=.22)$. The proportion of respondents who reported being up to date on any test increased from $60 \%$ to $69 \%$ in the intervention region and from $57 \%$ to $65 \%$ in the control region $(P=.82)$. The proportion who reported ever having FOBT rose in the intervention region from $61 \%$ to $63 \%$, whereas it fell in the control region from regions. We discussed the initial results with the CAC, which speculated that the intervention messages and materials may have reached residents in the control region. Analysis of follow-up data revealed that more than $40 \%$ of respondents in the control region reported having seen or heard at least 1 of our intervention products. We therefore conducted an exposure analysis of follow-up data comparing screening behaviors based on extent of exposure to intervention materials.

At follow-up, a higher percentage of respondents in the intervention region vs control region reported exposure to at least 1 colon cancer screening mate- 
rial $(65 \%$ vs $47 \%, P<.001)$. Less than $4 \%$ of baseline respondents reporting seeing colon cancer screening information in their community. Respondents in the control region saw fewer of the intervention materials than respondents in the intervention region (mean, 0.9 vs 1.7 items). Some respondents in the control region may have seen other materials on colon cancer prevention and believed they were part of our intervention materials; however, more than $6 \%$ of respondents in the control region reported having seen the farm auction flyer about colon cancer, a component that could not be confused with any other program's materials. We heard numerous anecdotes about our materials being shared in the control region and received requests for our materials from practices and clinicians in the control region. We know local newspapers in our intervention region have numerous subscribers in the control region who would have seen extensive newspaper components.

Greater exposure to our intervention materials was associated with a significantly higher rate of screening. The percentage of respondents who had ever had any test was $75 \%$ among those who reported they had not seen any of our materials, $78 \%$ among those who had seen 1 component, and $87 \%$ among those who had seen 5 or more components $(P<.05)$ (Figure 2$)$. Of note, for those who reported seeing just 1 of our intervention components, the combined measure of colonoscopy and sigmoidoscopy was 59\%, slightly higher than the statewide average $(57 \%)$; among those who

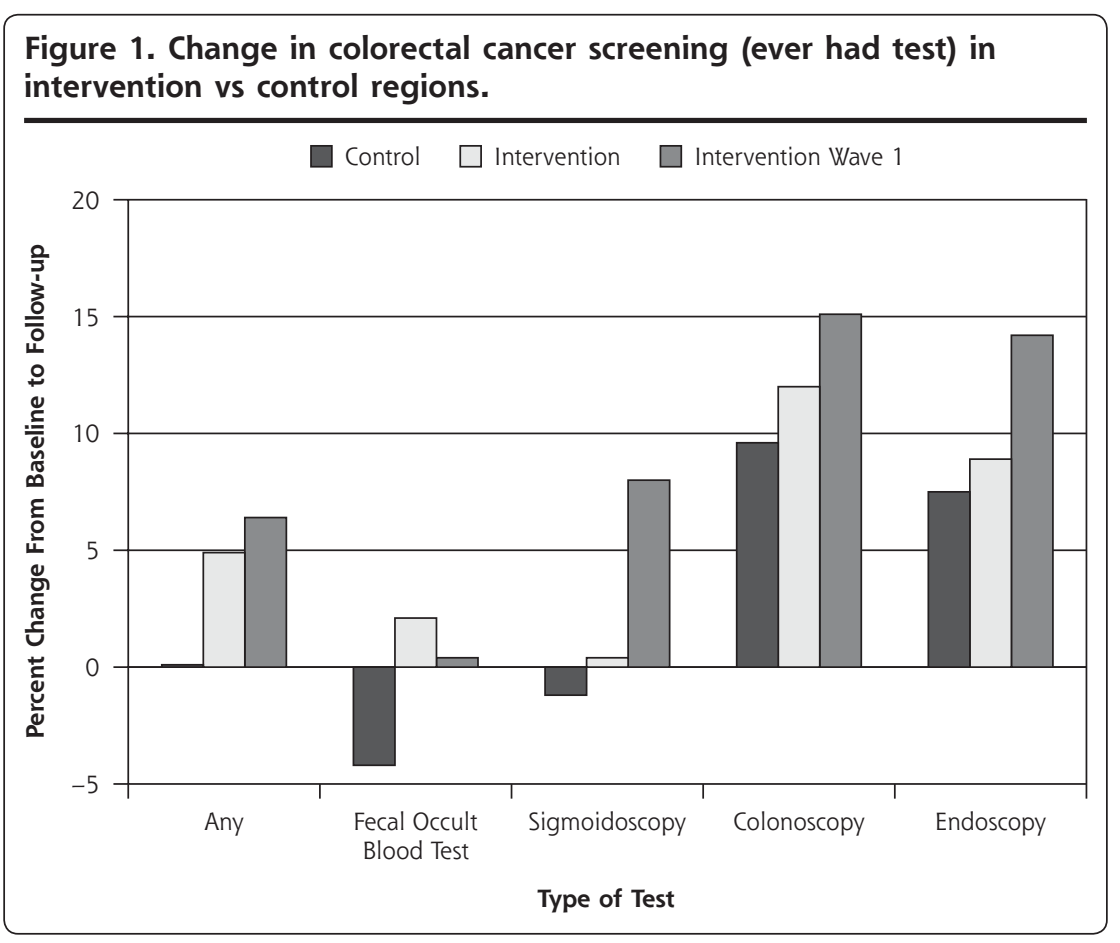

reported seeing 5 or more components, however, 70\% reported they had ever had sigmoidoscopy or colonoscopy, a value $13 \%$ higher than the statewide average.

Knowledge about colon cancer was significantly greater among those who had seen our intervention products, too. Exposed respondents were more likely to know colon cancer is preventable (adjusted odds ratio $=1.24 ; 95 \% \mathrm{CI}, 1.03-1.51)$ and that colon cancer is the second leading cause of cancer death in the United States (adjusted odds ratio $=1.15$; 95\% CI, 1.06-1.25). Finally, we found that exposure to materials increased the likelihood of having had a check-up in the past year (adjusted odds ratio $=1.16 ; 95 \% \mathrm{CI}$, $1.02-1.32$ ) and of having asked for a colon cancer test (adjusted odds ratio $=1.09 ; 95 \% \mathrm{CI}, 1.0-1.2)$.

\section{Hospital Screening Data}

Billing data from local hospitals for endoscopy services they provided between 2000 and 2007 showed a marked difference between regions (Figure 3). For sigmoidoscopy and colonoscopy, the control region hospitals had a $3 \%$ decrease, whereas hospitals in the intervention region had a $42 \%$ increase.

\section{DISCUSSION}

Our community-based participatory approach to develop and disseminate a colon cancer prevention message engaged hundreds of rural community members in a multicomponent educational and motivational campaign. The intervention region had an overall 5\% increase in screening compared with the control region; although this difference was not statistically significant, other evidence suggests a positive effect. The increase in screening rates based on exposure to multiple materials supports our multicomponent approach, and rates seen with multicomponent exposure exceeded those seen with single-component exposure. Community members who reported seeing 5 or more of our products were dramatically more likely to report having ever been tested or being up to date for colon cancer screening Our approach included general messages about colon cancer prevention in common media outlets (local newspapers) and 


\section{Figure 2. Impact of exposure on colorectal cancer screening $(n=1,048)$.}
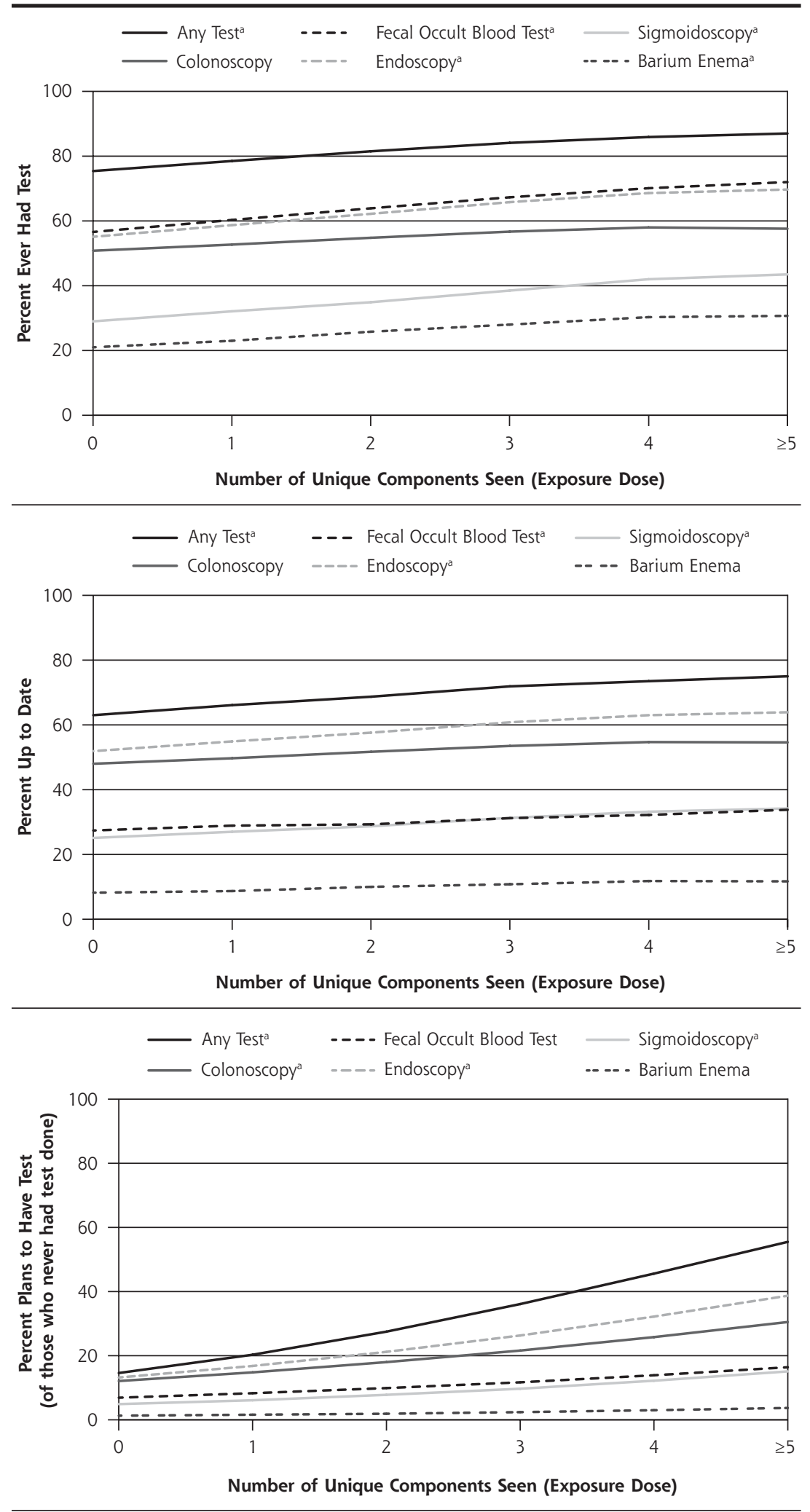

Note: endoscopy refers to colonoscopy and/or sigmoidoscopy.

a $P<.05$ very specific targeted messages and dissemination methods (farm auction flyer, talks at community organizations such as the Haxtun Gun Club). This combination resulted in some rural residents seeing and hearing a variety of materials. Without some of our less formal components (farm auction flyer), a sizable portion of the population may not have seen any messages related to colon cancer prevention.

The intervention materials did not promote one type of screening test, so it was surprising that the increases were mostly related to endoscopic screening. In conversations with clinicians in the community, we found that many are recommending colonoscopy for their patients who can afford it. During the intervention, many insurance companies and Medicare began providing coverage for colonoscopy, and a local educational program trained several rural primary care physicians to perform colonoscopy. A statewide program provided some funding for colonoscopy testing for uninsured patients of community health centers, equally distributed throughout both intervention and control regions. Although virtual colonoscopy was marketed heavily via local television, radio, and information displayed in clinicians' offices, there was no increase in this screening test. There were no local clinicians providing virtual colonoscopy in the region, so travel distance may have been a barrier to this screening test.

When a rural community is engaged in and activated around a pertinent health issue, a large number of individuals, organizations, health 
care professionals, and community leaders become collaborators as a result. Our program began with a Community Advisory Council of 10 members that grew to 15 . By the end of our program, more than 250 individuals had participated. Thirty-one community members partnered with 29 clinicians to provide 50 talks to more than 900 community members. Palm cards with local photos were placed in 162 locations; more than 1,450 were taken and another 900 were distributed at talks. Sixty-four unique ads and 45 unique personal stories were printed in 15 local newspapers.

We found dramatic cross-contamination of materials between our intervention and control regions. At first blush, this contamination created a problem for our study analysis; however, we believe that by activating the community this project had much more impact, leading to broader dissemination.

Statewide rates of Coloradoans who reported sigmoidoscopy or colonoscopy increased from $50 \%$ in 2004 to $57 \%$ in 2006 and $62 \%$ in $2008 .{ }^{17}$ The 2008 rate for sigmoidoscopy or colonoscopy according to the Behavioral Risk Factor Surveillance System was higher in Planning and Management Region 1 (the intervention region), at 58\%, than in Planning and Management Region 6 (the control region), at 50\%.

\section{Limitations}

Although the absolute increase in screening in the intervention region was greater than that in the control region, the difference was not statistically significant and could have been due to chance. The possibility exists that respondents who had been screened or were more knowledgeable about colon cancer were more likely to complete our survey, to notice materials and media stories, and to report seeing our materials. We heard from numerous community members that these materials directly prompted them to ask their local clinician about colon cancer prevention, however. Fewer than $4 \%$ of the baseline survey respondents reported seeing media or advertising messages about colon cancer, but numerous follow-up respondents reported seeing media messages about colon cancer, and could identify our unique products. The contamination of our control group interfered with our ability to conduct a meaningful intent-to-treat analysis; however, we were able to quantify the contamination and complete a rigorous exposure analysis.

\section{Implications}

On the basis of our data, we believe that our intervention resulted in increased testing to prevent colon cancer in rural eastern Colorado. A 5\% increase in overall screening in rural communities is an important finding and could result in thousands of additional screening tests and fewer colon cancer deaths. Because of the rural and remote setting, this project was not powered to detect a $5 \%$ change in screening, however, all the findings in this study move in the same direction and suggest that the intervention had a positive impact. We believe that based on the increase in testing to prevent colon cancer found in our study, a community-wide, multicomponent intervention can effectively increase colon cancer screening rates and represents an evidence-based approach to increase testing to prevent colon cancer.

To read or post commentaries in response to this article, see it online at http://www.annfammed.org/content/11/6/500.

Key words: Colon cancer prevention; rural; underserved; communitybased participatory research; practice-based research 
Submitted August 23, 2011; submitted, revised, February 4, 2013; accepted March 5, 2013.

Acknowledgments: The following members of the Community Advisory Council, High Plains Research Network, also contributed to this work: Ned Norman, Shirley Cowart, Maret Felzien, Connie Haynes, Mike Hernandez, Mary Petra Rodriquez, Norah Sanchez, Sergio Sanchez, Kathy Winkelman, and Steve Winkelman.

Funding support: This project was supported by Cooperative Agreement 5 U48 DP000054-02 from the Centers for Disease Control and Prevention.

Disclaimer: The contents of this article are solely the responsibility of the authors and do not necessarily represent the official views of the Centers for Disease Control and Prevention.

\section{References}

1. Centers for Disease Control and Prevention. 2001 Incidence and Mortality Data. http://apps.nccd.cdc.gov/uscs/TableV.asp?group =1a $\varepsilon$ Year $=2001 \varepsilon$ Gender $=$ MFERateType $=$ AgeadjType\&TableType $=$ M ORT. Accessed Sep 6, 2005.

2. American Cancer Society. Cancer Facts and Figures, 2004. http:// www.cancer.org/downloads/STT/CAFF_finalPW/Secured.pdf. Accessed Sep 6, 2005.

3. Walsh JM, Terdiman JP. Colorectal cancer screening: scientific review. JAMA. 2003;289(10):1288-1296.

4. Greenlee RT, Hill-Harmon MB, Murray T, Thun M. Cancer statistics, 2001. CA Cancer J Clin. 2001;51(1):15-36. Erratum in CA Cancer J Clin. 2001;51(2):144.

5. U.S. Preventive Services Task Force. Screening for colorectal cancer: recommendation and rationale. Ann Intern Med. 2002;137(2):129-131.

6. Centers for Disease Control and Prevention. Behavioral Risk Factor Surveillance System. 2004. http://apps.nccd.cdc.gov/brfss/page.asp? $y r=2004 \varepsilon$ state $=$ AllEcat $=$ WH\#WH. Accessed Sep 6, 2005.
7. Colorado Department of Public Health and Environment. State Summary of Colorado. 2002. BRFSS Data. http://www.cdphe.state. co.us/hs/brfss/colorado02.html. Accessed Oct 12, 2005.

8. Colorado Cancer Coalition. Colorado Cancer Plan 2006. http:// www.coloradocancercoalition.org/documents/CCC-Year_in_ReviewSept06_000.pdf. Accessed Aug 15, 2011.

9. Fazio L, Cotterchio M, Manno M, McLaughlin J, Gallinger S. Association between colonic screening, subject characteristics, and stage of colorectal cancer. Am J Gastroenterol. 2005;100(11):2531-2539.

10. Community Preventive Services Task Force. The Guide to Community Preventive Services. http://www.thecommunityguide.org/ cancer/screening/default.htm\#inter. Accessed Feb 2005.

11. Coughlin SS, Costanza ME, Fernandez ME, et al. CDC-funded intervention research aimed at promoting colorectal cancer screening in communities. Cancer. 2006;107(5 Suppl):1196-1204.

12. Young WF, McGloin J, Zittleman L, West DR, Westfall JM. Predictors of colorectal cancer screening in eastern Colorado: baseline data from the High Plains Research Network. J Rural Health. 2007;23(3): 238-245.

13. Rim SH, Zittleman L, Westfall JM, Overholser L, Froshaug D, Coughlin SS. Knowledge, attitudes, beliefs, and personal practices regarding colorectal cancer screening among healthcare professionals in rural Colorado: a pilot survey in the High Plains Research Network. J Rural Health. 2009;25(3):303-308.

14. Overholser L, Zittleman L, Kempe A, et al. Use of colon cancer testing in rural Colorado primary care practices. J Gen Intern Med. 2009; 24(10):1095-1100.

15. Zittleman L, Emsermann C, Dickinson M, et al. Increasing colon cancer testing in rural Colorado: evaluation of the exposure to a community-based awareness campaign. BMC Public Health. 2009;9:288.

16. Forsman G. Sampling Individuals Within Households In Telephone Surveys. http://www.amstat.org/sections/srms/Proceedings/ papers/1993_191.pdf. Accessed Oct 12, 2005.

17. Colorado Behavioral Risk Factor Surveillance System data. http:// www.cdphe.state.co.us/scripts/htmsql.exe/cohid/brfssfrm1.hsql. Accessed Apr 5, 2011. 